\title{
A Tribute to Steve White
}

\author{
Emilio Perucca $^{1}$
}

Received: 20 September 2016 / Accepted: 23 September 2016 / Published online: 1 October 2016

(C) Springer Science+Business Media New York 2016

I feel privileged to write this commentary as an introduction to this special issue of Neurochemical Research dedicated to Dr. Harold Steve White. In fact, I can think of no other scientist who more than Steve deserves to be honored for achievements related to advancing the pharmacological treatment of epilepsy. Steve is a true giant in this field, having worked tirelessly for almost 40 years, and continuing to work, to test potential new antiepileptic compounds and develop new models, thus leading the way in promoting novel paradigms for drug discovery.

Although I personally met Steve only in the late nineties, when the two of us were invited to speak at an international symposium in Germany, his name had been familiar to me for many years, because Dr. Harvey J. Kupferberg, who was then in charge of the Anticonvulsant Drug Screening Program at the National Institute of Health (NIH), had spoken to me very highly of a promising young scientist named Steve White. Many decades later, it is fair to say that those promises have been more than fulfilled. Over the years, I met Steve regularly at countless epilepsy meetings, we participated together in lecture tours, and we developed a strong friendship which extends to my wife, Tita, and his Kathryn. When in 2006 Dr. Kupferberg went into retirement and elected to step down from the Organizing Committee of the Eilat Conferences on New Antiepileptic Drugs (AEDs), a unique biannual event that brings together stakeholders

Special issue dedicated to Harold Steve White.

Emilio Perucca

perucca@unipv.it

1 International League against Epilepsy (ILAE), Department of Internal Medicine, University of Pavia and C. Mondino National Neurological Institute, Pavia, Italy involved in AED development, Steve was the obvious choice to replace his mentor in the Committee. From that moment we started an even closer collaboration that continues to the present day.

Steve was fortunate to start his career in the early 80 s at the University of Utah under the guidance of the late Dr. Dixon M. Woodbury, who was then the leading scientist worldwide in the pharmacology of AEDs. Steve's achievements in the following decades not only preserved the University of Utah's leadership in that area but also, more importantly, greatly contributed to the many advances in the treatment of epilepsy. In particular, in his 15-year capacity as Director and Principal Investigator of the NIH-funded Anticonvulsant Drug Development (ADD) Program, Steve was involved in the development and rational application of animal models of seizures and epilepsy, and played no small role in the discovery and characterization of several AEDs that were then introduced clinically over the following years. Although it would have been easy to run the ADD Program as a routine exercise, Steve never missed an opportunity to make the most of advances in scientific knowledge and expand available tools for the discovery of potentially better drugs, for example through the development of models of refractory seizures. In addition, he played a pioneering role in enlarging the range of applications of anticonvulsant drug models, particularly in the areas of neuroprotection and disease-modification. The latter objectives received particular impetus in 2011, when Steve took up the position of Research Director for CURE (Citizens United for Research in Epilepsy) and embarked on a strategic translational research plan focused on advancing therapies that prevent the development or the progression of epilepsy and could even lead to a cure for people with the disease.

Unlike several colleagues working in the same area, Steve does not merely utilize or develop experimental 
models, he also strives to understand the molecular and pathophysiological mechanisms involved in both the models and the disease process. The discovery by his team of the gene responsible for the occurrence of audiogenic seizures in the Frings mouse is a typical example of this approach, whose implications for therapeutic innovation are obvious.

Steve's excellence as a researcher is accompanied by unique qualities as a communicator and teacher. On countless occasions I have listened to his lectures around the world, and yet I am learning something new every time. I also admire his ability to transmit not just knowledge, but also enthusiasm for the discipline.

In recognition of all his achievements, Steve has received many national and international prizes and awards, and most recently the Ambassador for Epilepsy Award bestowed by the International League against Epilepsy and the International Bureau for Epilepsy. Yet, in spite of all those tributes, and a sprinkling of grey hair, Steve remains the same downto-earth and approachable man I met decades ago. Indeed, everyone who meets him can testify that he is always ready to listen and help, and that his warm, humble approach to inter-personal relationships contrasts with his top-level standing as a scientist.

Despite important progress in the current pharmacological armamentarium, at least one-third of people with epilepsy fail to achieve complete seizure control with available treatments. These people rely on the work and dedication of scientists like Steve to keep alive their hope for the discovery of more effective therapies that will control their seizures, or even cure their epilepsy. In the pursuit of these goals, Steve has now taken up new challenges at the University of Washington, and we all look forward to benefiting from his future research achievements which, surely, will not take long to materialize and to impact clinical practice. 